\title{
DNA bending and orientation-dependent function of YY1 in the c-fos promoter
}

\author{
Sridaran Natesan and Michael Z. Gilman' \\ Cold Spring Harbor Laboratory, Cold Spring Harbor, New York 11724 USA
}

\begin{abstract}
The assembly of multicomponent complexes at promoters, enhancers, and silencers likely entails perturbations in the path of the DNA helix. We present evidence that YY1, a ubiquitously expressed DNA-binding protein, regulates the activity of the c-fos promoter primarily through an effect on DNA structure. YY1 binds to and induces a phased DNA bend at three sites in this promoter. By use of a truncated c-fos promoter activity containing a single functional YY1 site, we show that YY1 represses promoter activity but that repression does not appear to be an intrinsic property of the protein in this context. Moreover, when the orientation of the YY1 site is reversed, YY1 activates the same promoter. Repression by YY1 is also alleviated by changing the relative phasing of factor-binding sites on either side of YY1. We conclude that the principal function of YY1 in this promoter is to bend DNA to regulate contact between other proteins. Thus, YY1 represents a new class of transcription factors that influences promoter function by affecting promoter structure rather than by directly contacting the transcriptional machinery. We provide evidence that the product of the male sex determination gene SRY may also belong to this class of structural factors.
\end{abstract}

[Key Words: YY1; promoter; DNA bending; SRY; transcription factor interactions]

Received September 30, 1993; revised version accepted October 27, 1993.

Activation or repression of transcription is largely dependent on the interaction of transcriptional activators and repressors with components of the basal transcription machinery (Ma and Ptashne 1987; Ptashne 1988; Levine and Manley 1989; Ptashne and Gann 1990; Dynlacht et al. 1991; Lin and Green 1991; Lin et al. 1991). The interaction between regulatory factors and basal machinery is often dependent on the position and/or the distance between their binding sites on the DNA. The DNA helix is rather inflexible over short distances of a few hundred base pairs (Wang and Giaever 1988). Therefore, interaction between proteins separated by small distances warrants sharp structural changes in the intervening DNA helix (Kerppola and Curran 1992). Some, but not necessarily all, transcription factors have the ability to induce structural changes in the DNA /Travers 1990; Kerppola and Curran 1993; Van der Vliet and Verrijzer 1993). In several cases, however, interaction between proteins separated by short distances on DNA may be mediated by so-called structural factors (Giese et al. 1992; Thanos and Maniatis 1992). Structural factors have no intrinsic activation or repression potential of their own but may instead induce structural changes such as bends in the DNA helix to facilitate the assembly of higher order protein-DNA complexes.

DNA bending and looping clearly play a role in the regulation of transcription, replication, and recombination in bacteria (Salvo and Grindley 1988; DeVargas et al.

'Corresponding author.
1989; Zinkel and Crothers 1991; Wang et al. 1992; PerezMartin and Espinosa 1993). One well-studied case involves integration host factor (IHF), an Escherichia coli protein required for the integration of $\lambda$ DNA into the bacterial chromosome (DeVargas et al. 1989). DNA bending induced by IHF brings the $\mathrm{P}^{\prime}$ and core arm sites of phage DNA into close proximity and allows the $\lambda$ integrase to promote looping of the intervening sequences. This process facilitates site-specific cleavage and recombination. Replacing the IHF-binding site with an intrinsic DNA bend is sufficient for juxtaposing the $\mathrm{P}^{\prime}$ and core sites, suggesting that the principal role of IHF in integration is to induce DNA bending (Nash 1990). DNA bending has also been reported to influence transcription in bacteria (Perez-Martin and Espinosa 1993).

Many mammalian DNA-binding proteins also bend DNA, but in general the role, if any, of bending in the function of these proteins is less clear. One example is LEF-1, a lymphoid-specific high mobiligy group (HMG) domain protein that binds to a site in the T-cell $\alpha$ enhancer and sharply bends the DNA (Giese et al. 1992). Reiterated LEF-1-binding sites have no transcriptional activity on their own. Rather, LEF-1 is proposed to act as an architectural element that mediates the assembly of a complex of other transcription factors at the enhancer. Another HMG domain protein, HMG I/Y binds to several sites in the $\beta$-interferon promoter (Thanos and $\mathrm{Ma}$ niatis 1992). Here, too, it has been proposed that one role of $H M G I / Y$ is to organize DNA structure to facilitate the assembly of a transcription factor complex at the 
virus-inducible element of this promoter. Many other mammalian transcription factors have been reported to bend DNA, including Fos, Jun, serum response factor, NF- $\mathrm{B}$, TFIID, Myc/Max, and Oct-1 /Gustafson et al. 1989; Schreck et al. 1990; Kerppola and Curran 1991, 1993; Verrijzer et al. 1991; Fisher et al. 1992; Giese et al. 1992; Horikoshi et al. 1992), although the functional significance of bending by these proteins is not known. Collectively, however, these studies suggest that the structural changes in the DNA induced by DNA-bending proteins may facilitate the formation of higher order DNAprotein complexes. In mammalian genes, DNA bending could be particularly important in allowing regulated access of distantly bound transcription factors to the basal transcriptional machinery at the promoter.

The c-fos proto-oncogene is a highly regulated gene where structural organization may be particularly crucial. Transcription of the c-fos gene is induced within minutes of exposure to a variety of extracellular factors (Rivera and Greenberg 1990). Remodeling of c-fos chromatin is apparent within $90 \mathrm{sec}$ of growth factor treatment (Feng and Villeponteau 1990), and induction of relevant DNA-binding proteins has been observed as early as $20 \mathrm{sec}$ after growth factor treatment (Sadowski and Gilman 1993). Thus, the assembly of active transcription complexes at the c-fos promoter occurs quickly and may be facilitated in some way. Moreover, c-fos transcription is activated independently by several distinct signal transduction pathways that act through discrete regulatory elements spread over $\sim 300 \mathrm{bp}$ of flanking sequence. Proteins bound at these sites must all have access to the basal machinery assembled at the c-fos promoter. Thus, it is likely that the spatial organization of the c-fos promoter is critical to its correct function.

Here, we present evidence suggesting that one protein responsible for the structural organization of the c-fos promoter is YY1. YY1, also known as NF-E1, $\delta$, UCRBP, and LBF, is a ubiquitously expressed zinc finger protein that has been identified in several different contexts (Hariharan et al. 1991; Park and Atchison 1991; Shi et al. 1991; Chen et al. 1992; Flanagan et al. 1992). YY1 is a very abundant protein with relatively degenerate DNAbinding specificity; thus, binding sites for YY1 are widely distributed in many cellular and viral promoters (Hahn 1992). In many instances, YYl appears to function as a transcriptional repressor (Park and Atchison 1991; Shi et al. 1991; Flanagan et al. 1992), whereas in other cases it appears to be an activator of transcription (Riggs et al. 1991).

Gualberto and co-workers (Gualberto et al. 1992) have recently proposed that a previously characterized protein, p62 ${ }^{\mathrm{DBF}} / \mathrm{MAPF} 1$ (Ryan et al. 1989; Walsh 1989), which binds to the c-fos serum response element (SRE), may be identical to YY1. In support of this hypothesis, we found that affinity-purified HeLa p $62^{\mathrm{DBF}}$ was antigenically related to YY1 and behaved identically to recombinant YY1 in a variety of biochemical assays (S. Natesan and M.Z. Gilman, unpubl.). We now report that YY1 binds to at least three sites in the mouse $\mathrm{c}$-fos promoter and that it bends the DNA at each site. By use of a sim- plified c-fos promoter derivative containing a single natural YY1 site, we show that YY1 has no intrinsic activation or repression activity on the promoter. Instead, it appears to organize the promoter to facilitate or interfere with the interaction of proteins on either side of its binding site. Consistent with this hypothesis, an unrelated DNA-bending protein can partially substitute for YYl at this site.

\section{Results}

YY1 binds to multiple sites in the mouse $c$-fos promoter

The mouse c-fos promoter contains several CCAT motifs that are found in most YY1-binding sites. Besides the SRE at -310 , potential YYl sites were identified at -255 and -55 . The latter site is situated between the major c-fos cAMP response element (CRE) and the TATA box. To determine whether YYl bound to these sites, we carried out mobility retardation assays with bacterially expressed YY1 and radiolabeled probes corresponding to each site. Figure $1 \mathrm{~A}$ shows that $\mathrm{YY} 1$ bound to all three probes (lanes 1,6,11). In each case, binding was abolished by YY1 antibody (lanes 2,7,12). Binding of YY1 to each probe was abolished by the inclusion of excess unlabeled oligonucleotide identical to the probe (lanes $3,8,13$ ), but not by unrelated oligonucleotides, indicating that YY1 interacts specifically with each of these probes. To determine whether YY1 bound the predicted sites in each probe, we carried out methylation interference experiments. Figure 1B shows the methylation interference analysis of YYl on the noncoding strand of each probe. In each case, the methylated guanines that interfere with YY1-DNA contact correspond to the predicted YY1-binding site. The sequence in the -55 region, 5'-GGAAGTCCATCCAT-3', contains two CCAT repeats. We observed partial interference at the guanosines complementary to both CCAT units, suggesting that YYl can bind to either CCAT sequence in vitro but not to both simultaneously.

\section{YY1 binding induces DNA bending at multiple sites in the mouse $c$-fos promoter}

While assaying affinity-purified HeLa $\mathrm{p} 62^{\mathrm{DBF}} / \mathrm{YY} 1$ on a variety of SRE-derived probes, we noted that the mobility of the protein-DNA complexes formed on different probes varied significantly. This behavior suggested that the protein might bend DNA. To test directly whether YYl binding induced DNA bending, we carried out circular permutation and phasing experiments. To generate probes for the circular permutation assays, oligonucleotides containing each of the three YYl sites in the c-fos promoter were cloned between two tandemly repeated polylinkers in the pBend2 vector (Kim et al. 1989). This plasmid allows the generation of probes that are identical in size and sequence but differ in the position of the YY1 site within the probe. Mobility retardation assays using circularly permutated probes containing the three 


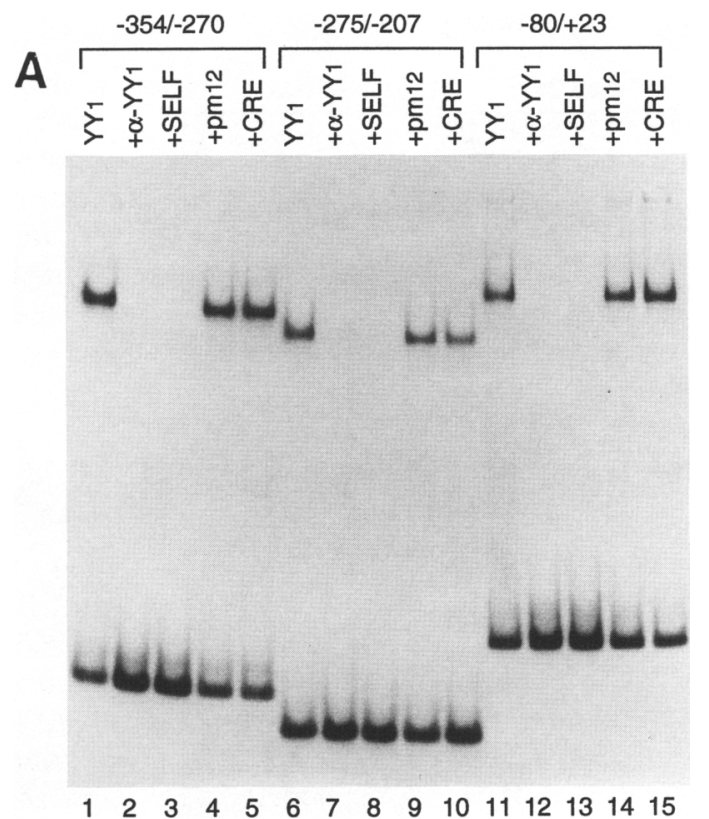

Figure 1. YY1 binds to multiple sites in the mouse c-fos promoter. (A) Mobility retardation assays of bacterially expressed YY1 on probes corresponding to three regions in the mouse c-fos promoter. The numbers at the top define the limits of the probe sequence in the mouse c-fos promoter. Competitor oligonucleotides (SELF) at 100 -fold molar excess, were identical to the probe (lanes $3,8,13$ ); (pm12) a derivative of the c-fos SRE that does not bind YY1 (Ryan et al. 1989) (lanes 4,9,14); (CRE) corresponding to the somatostatin CRE (lanes $5,10,15)$ In lanes $2,7,12$, hybridoma supernatant $(2 \mu 1)$ containing monoclonal anti-YY1 antibody $[\alpha Y Y 1-I g 3-1$ (Seto et al. 1991/] was added to the binding reaction before the addition of probe. $(B)$ DMS interference assay showing the methylated guanines that interfere completely

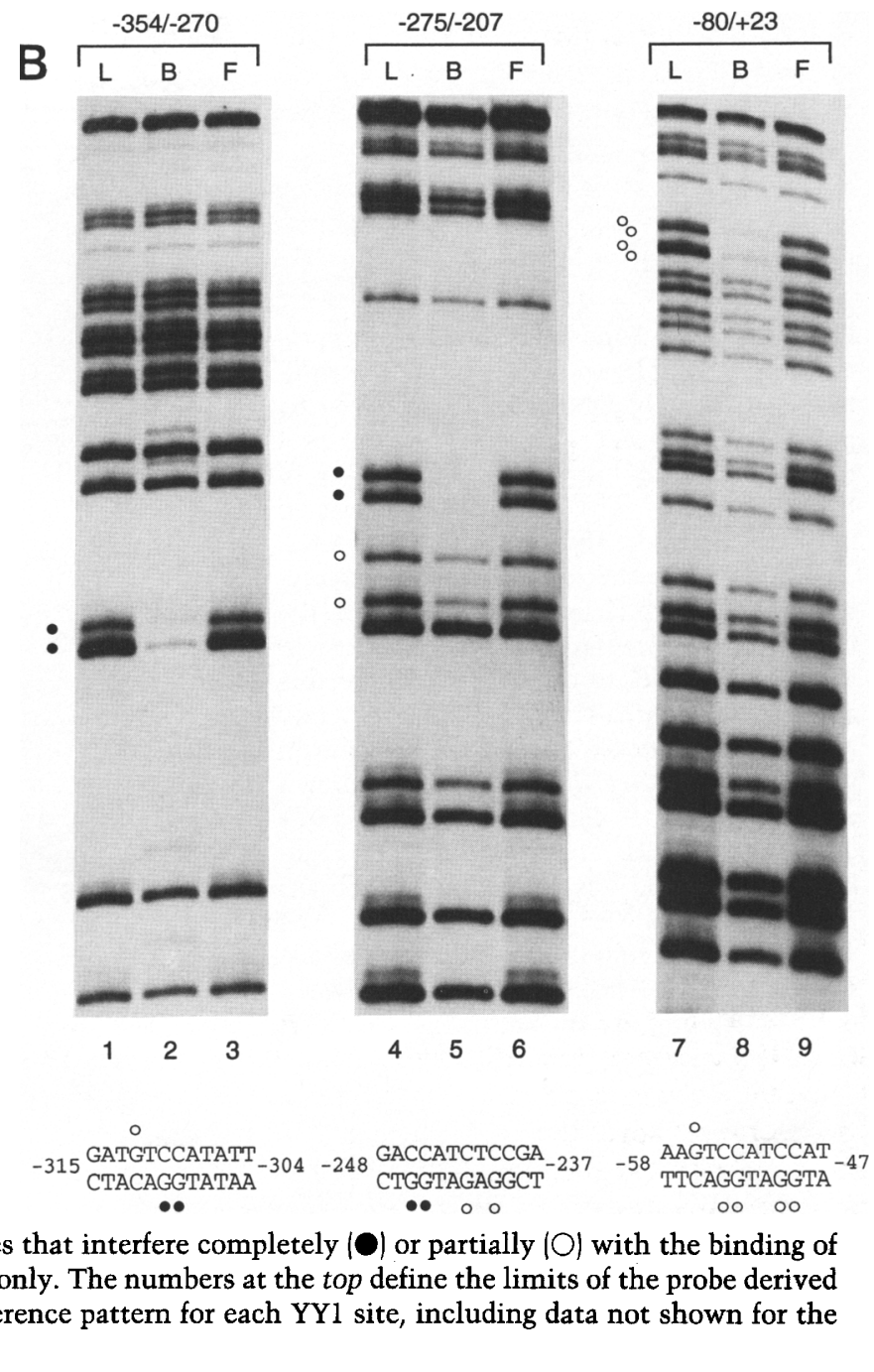
from mouse c-fos promoter. A summary of the methylation interference pattern for each YYl site, including data not shown for the upper strand, is shown at the bottom of the corresponding panel.

YYl sites are shown in Figure 2A. In each case, the mobility of the YY1-probe complex in the gel varied depending on the location of the YYl site within the probe. The migration of the YY1-DNA complex was slowest when the YY1 site was at the center of the probe. The fastest migrating complexes were observed when the YYl sites were situated near an end of the probe. These observations indicate that YYl is altering the shape of the DNA molecule.

The circular permutation assay allows localization of the point of distortion in the DNA helix induced by protein binding. For the SRE and -255 sites, the putative bend center mapped to the center of the YY1 site between the $\mathrm{C}$ and A nucleotides in the CCAT core / see Materials and methods). Because the bands generated with the -55 probe represent a mixture of two complexes at different positions in the probe, it was not possible to map a bend center. Comparison of the bend angle induced in each probe by YYl with reference probes containing intrinsic bends showed that YY1 bends the DNA to $\sim 86^{\circ}$ and $78^{\circ}$ at the SRE and -255 sites, respectively (see Materials and methods). Again, because the -55 probe carries two YY1 sites, we could not unambiguously measure the bend angle, but the magnitude of bending in this probe is similar to the others.

The change in the mobility of a protein-DNA complex can be caused by a variety of distortions of the DNA helix, including protein-induced bending, cruciforms, H-DNA, and triple helix formation (Kerppola and Curran 1991). Circular permutation analysis localizes the distortion in the DNA structure, but it does not identify the nature of the distortion. The presence of protein-induced bends in DNA is diagnosed more accurately using phasing analysis (Wu and Crothers 1984; Zinkel and Crothers 1987). This assay is based on the phase-dependent cooperative interaction between two bends in a DNA molecule. If two bends are in the same phase, the bends cooperate, resulting in an additive degree of DNA bending. If the bends are in opposite phases, they cancel and reduce the overall degree of bending. To understand whether YY1 induces true DNA bending, we used this phase-sensitive detection method. For this assay, an oli- 
Figure 2. YYl bends the mouse c-fos promoter at multiple sites. $|A|$ Circular permutation analysis of DNA bending induced by purified recombinant YY1. Each panel is a representative mobility retardation assay of YY1 complexes on circularly permutated probes containing the indicated YY1 sites. The numbers at the top of each panel correspond to the nucleotide sequences in the mouse c-fos promoter that were inserted in the $\mathrm{pBend} 2$ vector to generate probes for this assay. A schematic diagram of the tandemly repeated restriction sites and the position in which the YYl sites were cloned $(\square)$ is shown at the bottom. $(B)$ Phasing analysis of YY1 binding to the SRE site. A representative mobility retardation assay using recombinant YYl and phased SRE probes is shown. The phased probes contained a variable nucleotide spacer, indicated above each lane, between the YYl-binding site and an intrinsically bent DNA sequence (see Materials and methods).

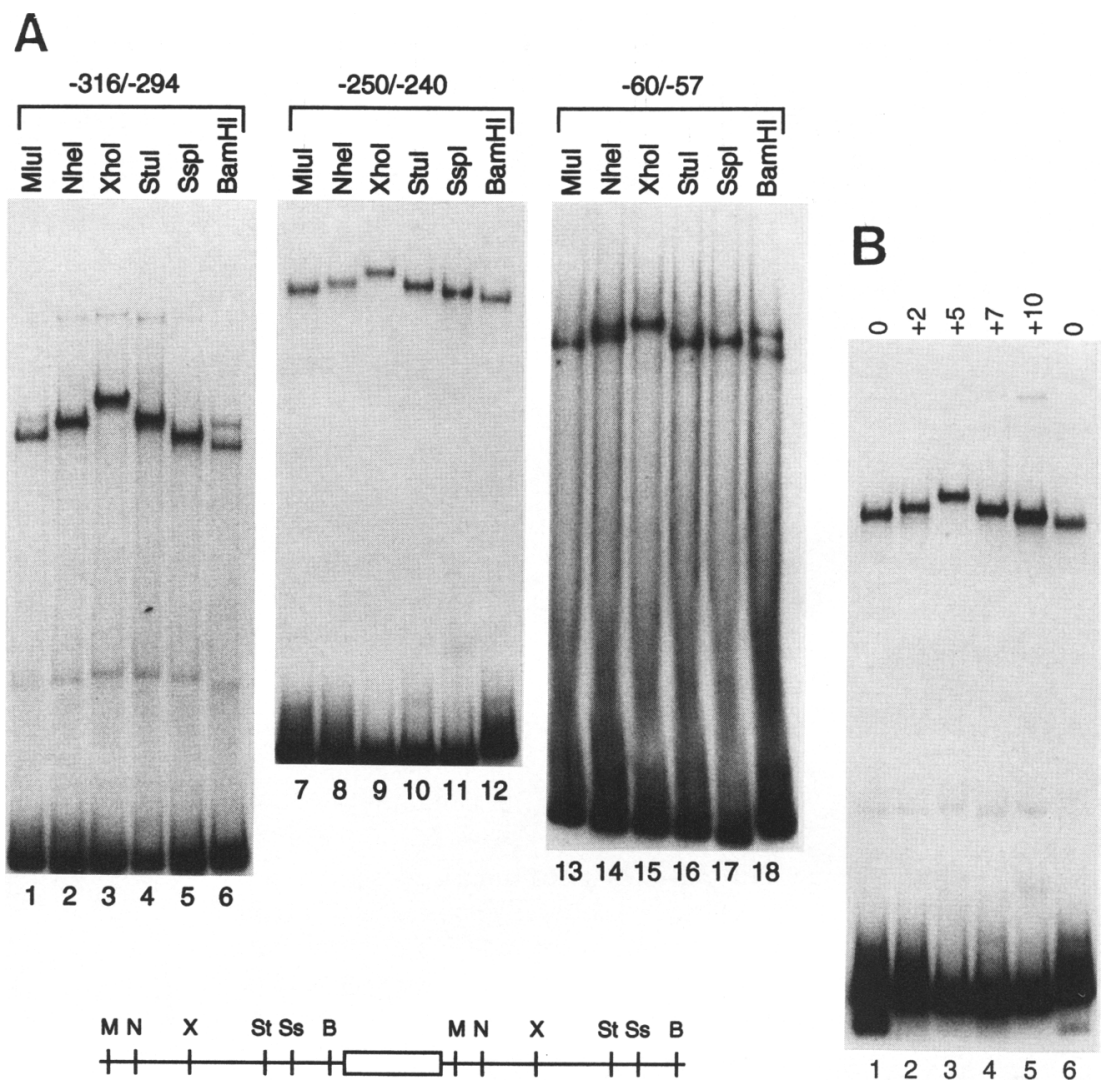

gonucleotide containing the -310 YY1-binding site was inserted in front of an intrinsic AT-rich sequence known to bend DNA toward the minor groove (Zinkel and Crothers 1987). Phase changes between SRE and the intrinsic bend were achieved by inserting 2, 5, 7, or $10 \mathrm{bp}$ between the sites. Figure $2 B$ shows that the slowest migrating YY1-DNA complex contained a 5-bp insertion, whereas the fastest migrating complex contained a 10-bp insertion. These results show that YY1 is able to induce a fixed bend in the DNA that can cooperate with or counteract the effect of the intrinsic DNA bend. Calculation of the bend angle from phasing experiments indicated that YY1 bends the DNA to $\sim 78^{\circ}$. This value agrees well with the angles calculated from the circular permutation experiments.

\section{YY1 is a repressor of CRE-dependent c-fos promoter activity}

The bending and phasing data suggest that YYl can bend the mouse c-fos promoter at at least three different sites. Thus, YY1 has the potential to induce significant curvature in the c-fos promoter. It is likely that a distortion of such magnitude would have a significant impact on c-fos promoter function. To determine whether DNA bending by YY1 plays a role in the activity of the c-fos promoter, we performed a series of transfection experiments with a simplified c-fos promoter carrying sequences from -71 to +109 fused to the bacterial CAT gene. This promoter consists of the major c-fos CRE $(-68$ to -61$)$ and the TATA box $(-34$ to -29$)$, separated by the dual YY1 sites $(-54$ to -47$)$ (Fig. 3A).

To determine the function of YY1 in this region of the c-fos promoter, we introduced mutations into the YY1 sites (Fig. 3A). Wild-type and mutant promoter plasmids were transiently transfected into HeLa cells, and extracts of the transfected cells were assayed for CAT activity. Figure 3B shows that when both potential YY1 sites in the promoter were mutated, promoter activity increased approximately fourfold (cf. lane 2 with lane 1). Thus, in the wild-type c-fos promoter the YYl sites repress transcription. This effect was reproduced by mutating only the promoter-distal YY1 site (lane 3), whereas mutation of the promoter-proximal site had no effect (lane 4). Thus, the distal CCAT appears to be the functional element for repression in vivo.

The repression activity attributed to YY1 in the c-fos promoter could be the result of an intrinsic ability to repress the activity of the basal transcription machinery or to an ability to interfere with function of an activator bound at the neighboring CRE. To distinguish between these possibilities, we made additional mutations that abolish the activity of the CRE (Fig. 3A) and tested these promoters by transfection in HeLa cells. Figure $3 \mathrm{~B}$ shows that consistent with an earlier deletion analysis of the mouse c-fos promoter (Gilman et al. 1986), mutation of the CRE site led to a significant reduction in promoter activity (cf. lane 5 with lane 1). In contrast to promoters 


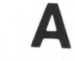

\section{$-71 w t$}
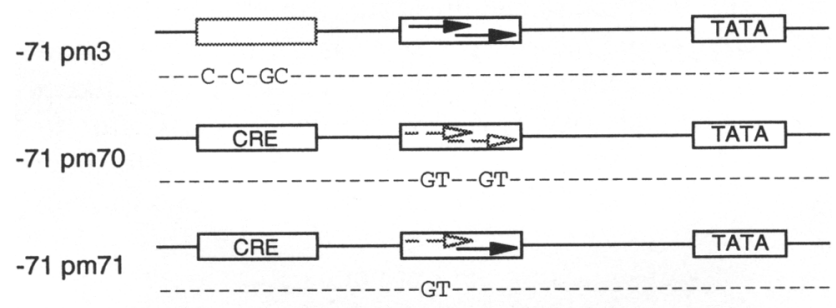

$-71 \mathrm{pm} 72$
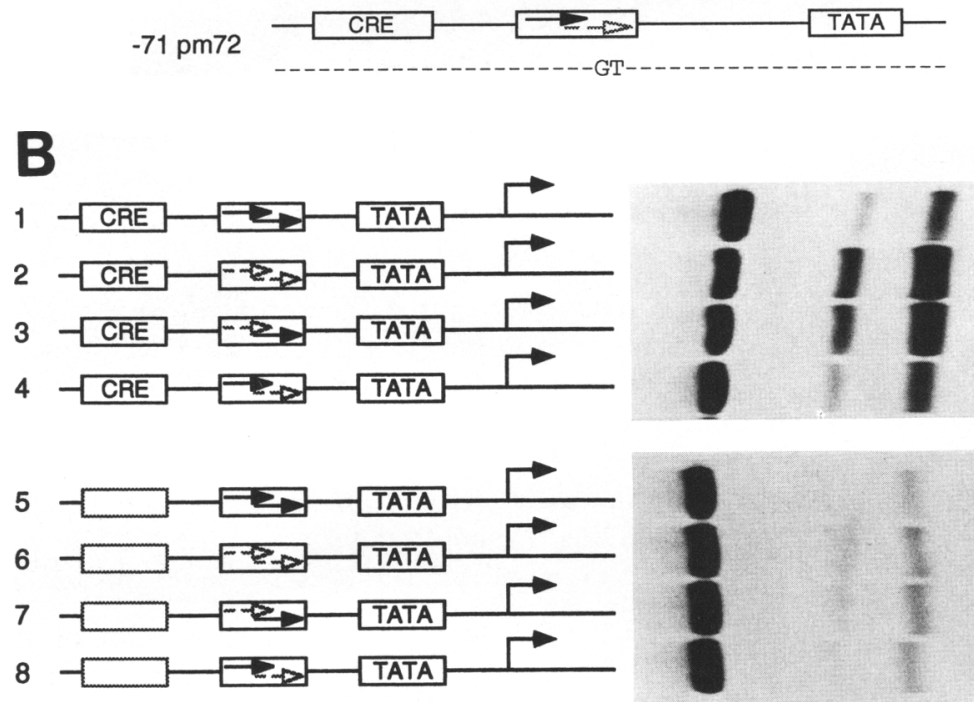

C

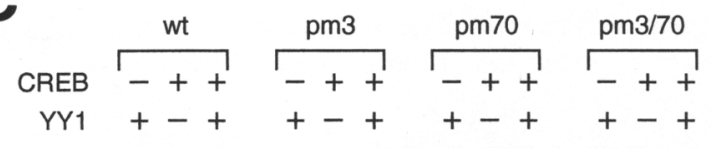

$14.5 \pm 2.2$

Figure 3. YYI is a repressor of CRE-dependent transcriptional activation. $(A)$ Schematic diagram of reporter plasmids used in $57.1 \pm 7.5$ this experiment. The arrows indicate the $53.9+4.1$ number and orientation of either wild-type $53.9 \pm 4.1$ (solid) or mutant (open) YY1 sites. The se15.4 \pm 4.3 quences between -71 and the TATA box in the wild-type plasmid are shown at the top. The sequences under the schematic diagram of each mutant show the substitutions relative to wild type. $(B)$ HeLa cells were transfected with reporter plasmids $-71 \mathrm{wt}$ (lane 1), $-71 \mathrm{pm} 70$ (lane 2), $-71 \mathrm{pm} 71$ (lane 3), $-71 \mathrm{pm} 72$ (lane 4), $-71 \mathrm{pm} 3$ (lane 5), $-71 \mathrm{pm} 3 / 70$ (lane 6), $-71 \mathrm{pm} 3 / 71$ (lane 7 ), or $-71 \mathrm{pm} 3 / 72$ (lane 8 ). Extracts were prepared from the cells $\sim 36 \mathrm{hr}$ after transfection and assayed for CAT activity. Assays were normalized for the $\beta$-galactosidase internal control. A representative experiment is shown. The numbers at right are the average values and standard deviation derived from a minimum of three experiments. (C) Mobility retardation assays of bacterially expressed YY1 and in vitro-translated CREB protein on probes derived from -71wt (lanes 1-3), $-71 \mathrm{pm} 3$ (lanes 4-6), $-71 \mathrm{pm} 70$ and $-71 \mathrm{pm} 3 / 70$ reporter plasmids. Probes carried sequences from -71 to +23 . The arrows indicate protein-DNA complexes formed by $\mathrm{YY} 1(\mathrm{Y})$ or CREB $(\mathrm{C})$ or both $(\mathrm{Y}+\mathrm{C})$. The free probe was run out of the gel to enhance resolution of the different protein-DNA complexes.

containing an intact CRE, mutation of the YY1 sites in the CRE mutant had no significant effect on promoter activity (lanes 6-8). Assuming that the residual CAT activity measured from the mutant promoters arises from transcripts initiating at the c-fos promoter, these observations suggest that the YY1 sites in this promoter have no intrinsic repression activity in the absence of a functional CRE. This result argues against any direct action of YY1 on the basal transcription machinery at the c-fos promoter and suggests instead that YYl exerts its activity via proteins bound at the CRE.

One mechanism by which YY1 could interfere with the function of the CRE is by competitively excluding the binding of proteins to the CRE. To rule out this pos- sibility, we performed DNA-binding assays with recombinant YY1 and cAMP response element binding (CREB) protein (Hoeffler et al. 1988; Gonzalez et al. 1989; Berkowitz and Gilman 1990), which binds to the c-fos CRE (Sassone-Corsi et al. 1988; Yamamoto et al. 1988; Berkowitz and Gilman 1990). Figure 3B shows that $\mathrm{CREB}$ and YY1 can each bind to the c-fos promoter (lanes 1,2 . When the proteins were added together, a complex of slower mobility was observed, suggesting that CREB and YYl can co-occupy the promoter (lane 3). This putative ternary complex failed to form on probes that carried mutations either in the CRE or the YY1 sites, indicating that the complex contains both proteins. Binding of CREB and YY1 to this probe appeared to be indepen- 
dent events and showed no evidence of positive or negative cooperativity. These data suggest that YY1 does not act by affecting the binding of CREB or similar proteins to the CRE.

\section{Activity of the YY1 site is orientation dependent}

Our data suggest that YY1 normally functions as a repressor in the truncated c-fos promoter and that its ability to repress promoter activity depends on the presence of an intact upstream CRE. Because YYI bends DNA to which it binds, we speculated that its repression activity might be attributable to a structural distortion of the DNA helix that prevents proteins bound at the CRE from interacting optimally with the basal transcription machinery assembled downstream of the YY1 site. If DNA bending is responsible for the activity of YY1 in the c-fos promoter, we reasoned that reversing the orientation of the YYl site and, therefore, changing the angle of the induced bend would have a dramatic effect on promoter activity. To test this hypothesis, we created a mutant c-fos promoter in which a 10-bp sequence carrying the YY1 site-essentially a full helical turn of the DNA - was reversed (Fig. 4A). As a control we made an additional mutant in which the reversed segment carried mutations that abolish YY1 binding. These constructs were tested by transient transfection assay in HeLa cells. As shown previously in Figure 3B, mutation of the YY1 sites in the c-fos promoter elevated promoter activity, by approximately threefold in this experiment (Fig. 4B, lanes 1,2 ); the activity of the $p m 70$ promoter (lane 2) can be regarded as the baseline activity in the absence of YYl sites. When the orientation of the YYI sites was re- versed, promoter activity increased nearly 6 -fold over the activity in the absence of YY1 sites and 15-fold relative to the wild-type promoter (lane 3). Thus, in the natural orientation the YY1 site represses promoter activity, whereas in the reverse orientation the YYl site activates the promoter. Activation is most likely attributable to the YY1 site and not a fortuitous activator site created in this construct, because activation of the reversed promoter was prevented by substitutions that abolish YY1 binding (lane 4). The ability of the reversed YY1-binding site to activate the promoter, like the ability of the natural sequence to repress, was absolutely dependent on the presence of an intact upstream CRE (lanes 5-8). Thus, activation, like repression, appears not to be an intrinsic activity of YYl at this promoter. Rather, in one orientation YY1 appears to facilitate activation by CREbinding proteins, whereas in the other it interferes with activation. These data are consistent with the idea that the activity of YY1 on the c-fos promoter arises from its ability to bend the DNA and not from any intrinsic activation or repression activity.

\section{YY1-dependent activation and repression of CREB activity in Drosophila cells}

Although we have attributed the activities of the YY1 sites in the c-fos promoter to YYl and the CRE sites to CREB, we cannot be certain that these are the proteins functioning at these sites in HeLa cells. To circumvent this problem, we took advantage of the observation that Drosophila SL2 cells lack detectable YY1 activity (Seto et al. 1991). Thus, we could determine whether the activities we observed in HeLa cells could be recapitulated
Figure 4. The activity of YY1 on the mouse c-fos promoter is orientation dependent. $(A)$ Schematic diagram of the -71 wt and mutant reporter plasmids, depicted as described in the legend to Fig. 3. $(B)$ HeLa cells were transfected with reporter plasmids $-71 \mathrm{wt}$ (lane 1), $-71 \mathrm{pm} 70$ (lane 2), $-71 \mathrm{pm} 73$ (lane 3), -71pm74 (lane 4), $-71 \mathrm{pm} 3$ (lane 5), $-71 \mathrm{pm} 3 / 70$ (lane 6$),-71 \mathrm{pm} 3 / 73$ (lane 7$)$, or $-71 \mathrm{pm} 3 / 74$ (lane 8 ). Cells were harvested, and extracts were assayed for CAT activity. A representative experiment is shown. Average CAT conversions and standard deviation from a minimum of three experiments are shown at right. The assay in lane 3 is outside the linear range of the assay and thus likely underestimates the activity of this construct.

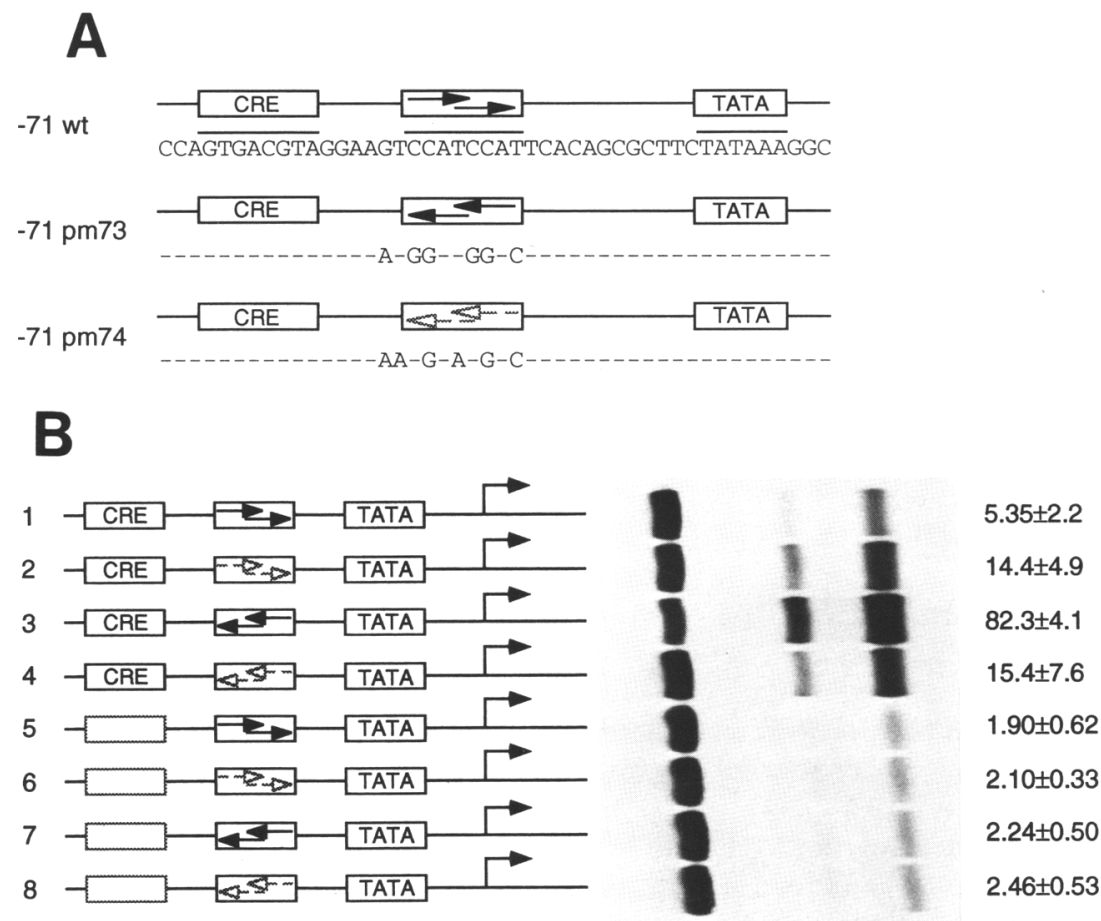


in SL2 cells with exogenously supplied YY1 and CREB. When the truncated mouse c-fos promoter was transfected into SL2 cells, it was very weakly active (Fig. $5 \mathrm{~A}, \mathrm{~B}$, lanes 1). Cotransfection of an expression vector producing human CREB activated the promoter approximately sixfold (lanes 3), indicating that activity of any endogenous CRE-binding proteins in SL2 cells is relatively low. The activity of the human CREB protein on the $\mathrm{c}$-fos promoter could be completely abolished by YY1 (lane 4). Thus, authentic YY1 is capable of repressing promoter activity resulting from an authentic CREB. Repression by YY1 required the presence of YY1-binding sites (lanes 12,16) and, therefore, is not attributable to squelching. Moreover, on the promoter carrying the reversed YYl site, introduction of YYl activated rather than repressed CREB-dependent transcription, although the magnitude of activation was less than that observed in HeLa cells (lane 8). Finally, YY1 alone neither repressed nor activated the promoter in the absence of cotransfected CREB, indicating that it has no intrinsic activation or repression activity in SL2 cells. Thus, the function of YY1 in the SL2 cells is identical to that inferred from the HeLa experiments. YYl functions in an orientation-dependent fashion to repress or augment the transcriptional activity of CREB on the c-fos promoter.

\section{Altered phasing of the CRE and TATA elements abolishes repression}

If YY1 is bending DNA such that CREB is bent away from the TATA element in the natural promoter but toward the TATA element in the reversed construct, then the precise phasing of the CRE and TATA elements on the DNA helix should also be critical to promoter function. Specifically, we imagine that insertion of $5 \mathrm{bp}$ between the CRE and the TATA element should effectively rotate CREB by half a helical turn relative to the transcription complex. If the DNA is bent such that CREB is bent away from the basal machinery in the wildtype promoter, then this insertion should bring CREB to the opposite face of the helix, closer to the basal machinery. Consequently, the promoter should be activated by such an insertion. Figure 6 shows that consistent with this prediction, insertion of $5 \mathrm{bp}$ between the CRE and YYl site activated the promoter by fourfold (Fig. 6B, lane 2). Inserting an additional $5 \mathrm{bp}$, thereby rotating the CRE back to the original helical face, restored promoter activity to wild-type level (lane 3). Identical results were observed when 5- and 10-bp insertions were placed between YYl and the TATA box (lanes 4,5). That insertions on either side of YY1 had the same effect argues against the idea that specific contacts between YY1 and CREB or between YY1 and basal transcription factors are required for its activity. Rather, these data support the idea that the positioning of the CRE and TATA elements relative to each other determines promoter activity, and it is the function of YY1 to fix this positioning.

\section{An unrelated DNA-bending protein partially mimics YY1 function}

Taken together, our data argue that the function of YY1 in the simplified c-fos promoter is to coordinate the tertiary structure of promoter DNA and thereby to direct the interactions among other proteins at the promoter. If this is the sole function of YYl, then its activity should be mimicked by an unrelated DNA-bending protein. It was possible for us to test this hypothesis because the
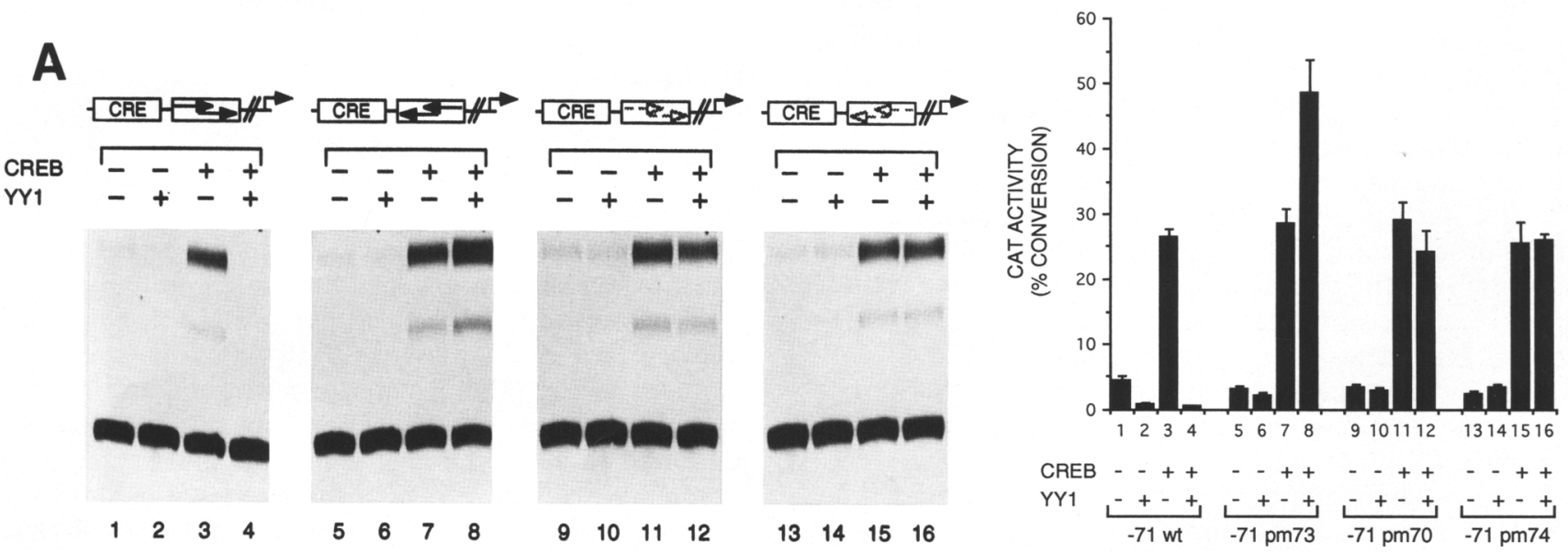

Figure 5. Orientation-dependent activation or repression of CREB-dependent transcription by YY1 in Drosophila SL2 cells. $(A)$ Drosophila SL2 cells were transfected with -71wt (lanes 1-4), -71pm73 (lanes 5-8), -71pm70 (lanes 9-12), or -71pm74 (lanes 13-16) alone, or with effector plasmids expressing YY1 and/or CREB, as indicated. Cells were harvested $36 \mathrm{hr}$ after transfection, and CAT activity was measured from extracts, following normalization for $\beta$-galactosidase activity. A representative experiment is shown. (B) Average CAT activity and standard deviation from three SL2 transfection experiments. 
Figure 6. Changing the phasing between the CRE and TATA box elements counteracts YYl-mediated repression. (A) Schematic diagram of reporters containing either 5- or 10-base insertions at the positions shown. (B) HeLa cells were transfected with reporter plasmid $-71 \mathrm{wt}$ (lane 1), -71pm75 (lane 2), - 71pm76 (lane 3), -71 pm77 (lane 4), or -71 pm78 (lane 5). Cells were harvested and assayed for CAT activity. A representative experiment is shown. The numbers at right indicate the average CAT activity and standard deviation from three experiments.
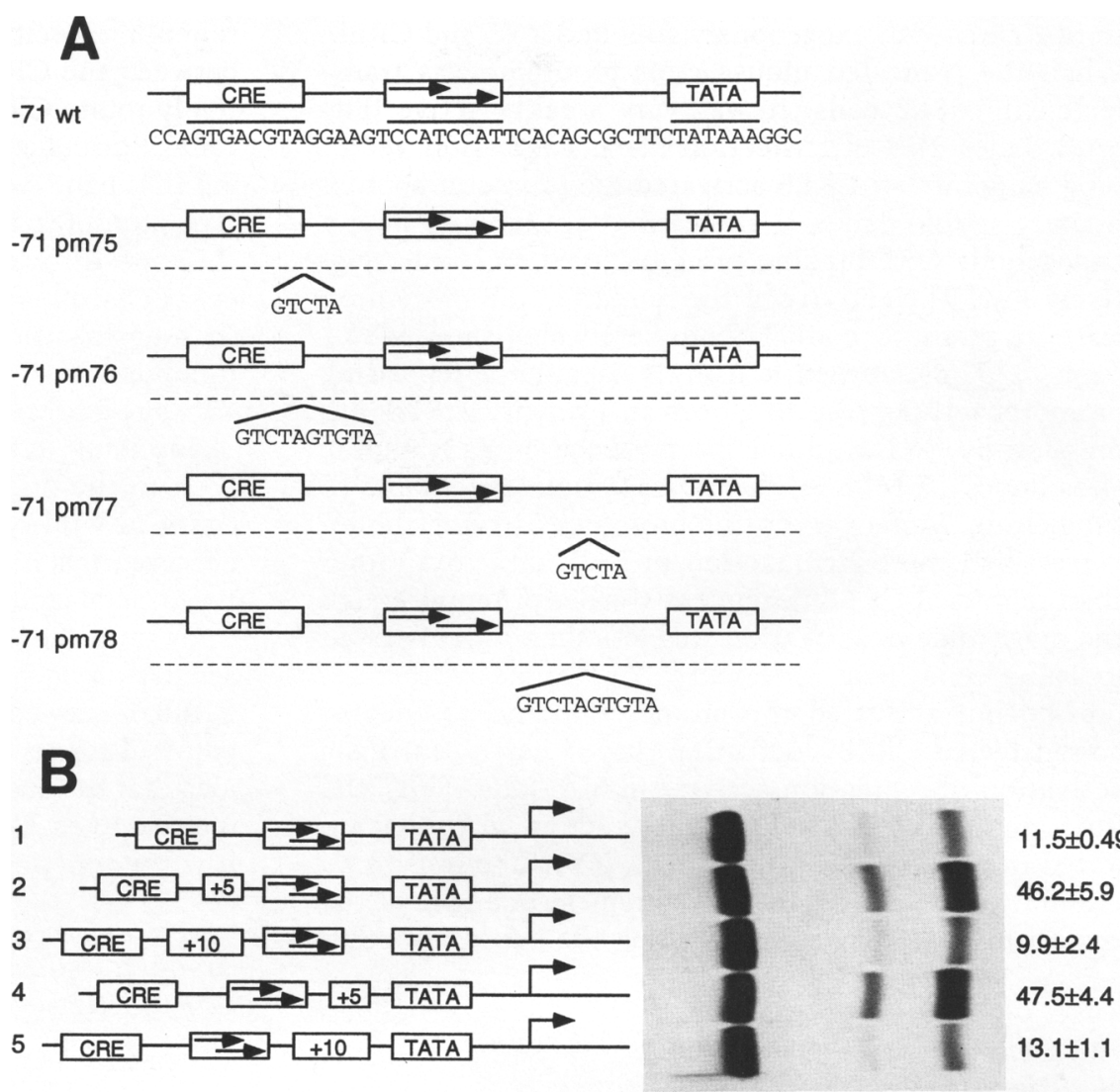

product of the mouse testis-determining factor gene, SRY (Gubbay et al. 1990), is a DNA-bending protein that binds sequences similar to those bound by YY1 /Giese et al. 1992). Despite overlapping DNA-binding specificity, SRY and YYl are completely unrelated in structure. SRY is an HMG domain protein, whereas YY1 is a member of the zinc finger family. If DNA bending by YY1 is its critical activity at the c-fos promoter, then SRY ought to behave similarly in our assays. It is unlikely, however, that they would behave identically, because the center, direction, and magnitude of the DNA bends induced by the proteins almost certainly differ. Indeed, both the direction and magnitude of one characterized SRY-induced bend differ significantly from the bend induced in the c-fos promoter by YY1 (Giese et al. 1992). Nevertheless, if bending is the pertinent function of YY1, any activity, positive or negative, elicited by SRY ought to be orientation dependent and require functional CREB.

To test these ideas, we placed the SRY cDNA into a Drosophila expression vector and examined its activity on the c-fos promoter in SL2 cells. Figure 7 shows that SRY does share some properties with YYl. First, like YY1, SRY repressed the stimulatory activity of CREB on this promoter (lane 4); this activity required an intact SRY-binding site (lane 12). Second, repression by SRY required the presence of active CREB (lane 2), showing that repression in this assay is not an intrinsic activity of SRY but rather a manifestation of its ability to influence the function of a neighboring protein. Third, SRY function was orientation dependent, because in the reverse orientation, SRY did not significantly repress CREB activity (lane 8). Here, SRY differs from YY1, which modestly activates the reversed construct in SL2 cells (Fig. 5). Thus, SRY functions as an orientation-dependent repressor of CREB activity, mimicking many of the activities of YY1. Because these proteins share no obvious function besides DNA binding and DNA bending, we argue that site-specific DNA bending is the principal role of YY1 in the c-fos promoter.

\section{Discussion}

YY1 is an unusual protein in that it both represses and activates transcription, depending on the promoter context (Hahn 1992). It has been proposed that this dual activity implies the presence of two distinct functional domains in the protein, one for repression and one for activation (Shi et al. 1991). Here, we provide evidence that activation and repression by YY1 may be manifestations of the same biochemical activity, the ability to bend DNA. Thus, YY1 may define a new class of transcription factors that organize the topology of the transcription complex rather than influence its assembly directly.

Several observations support this idea. First, we find that binding of YY1 to DNA is consistently associated 


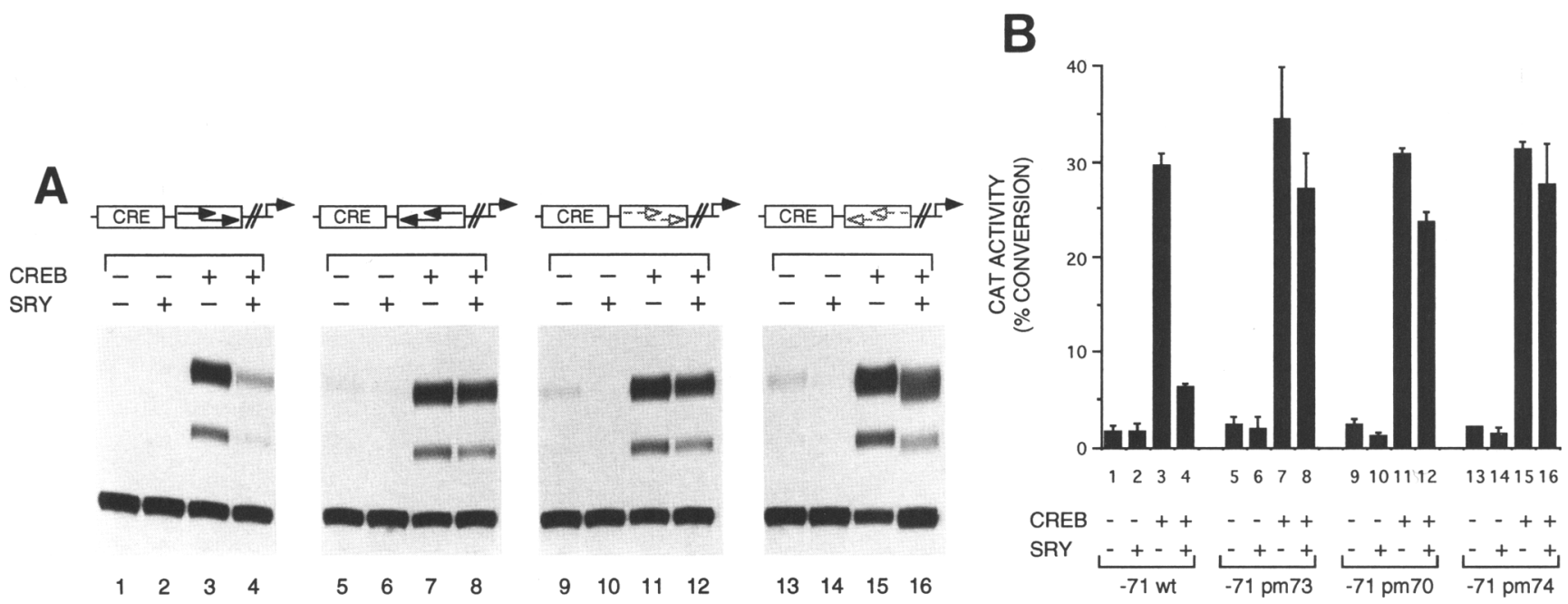

Figure 7. Testis-determining factor, SRY, is an orientation-dependent repressor of CREB protein activity in Drosophila SL2 cells. $(A)$ Drosophila SL2 cells were transfected with -71 wt (lanes 1-4), -71 pm73 (lanes 5-8), -71 pm70 (lanes 9-12) or -71 pm74 (lanes 13-16) alone or with the indicated effector plasmids. Cells were harvested and assayed for CAT activity. A representative experiment is shown. $(B)$ Average CAT activity and standard deviation from three SL2 transfection experiments.

with the formation of a precisely phased bend in the DNA helix. Second, we find that YY1 activity at the c-fos promoter in vivo has the unusual property of being orientation dependent. Third, the activity of YY1, both positive and negative, depends on the presence of an active CRE 5' to the YY1 site; YY1 itself appears to have no intrinsic activation or repression activity on this promoter. Fourth, rotating either the CRE or the TATA element to the opposite face of the helix mimics the effect of changing the direction of the YY1 bend and activates the promoter. Fifth, the effect of YY1 on c-fos promoter function can be mimicked in part by SRY, an unrelated protein that can bind the YY1 site and bend DNA.

Together, these observations suggest that the principal function of YY1 in this promoter is to alter the path of the DNA helix. In its normal configuration, we imagine that YYl bends the DNA such that CREB is oriented away from the transcription complex. Reversing the YY1 site changes the path of the DNA helix so that CREB is now oriented toward the transcription complex, allowing it to interact more readily. Alternatively, insertion of $5 \mathrm{bp}$ on either side of the YY1 site rotates CREB by half a helical turn relative to the transcription complex, so that the natural YY1-induced bend promotes rather than prevents contact.

Clearly, however, YYl may have different functions in other promoters. It could, for example, interact competitively with proteins that recognize an overlapping site or facilitate the binding of other proteins via direct protein-protein contact. Furthermore, it could have intrinsic activation and repression functions that work in a context-dependent fashion, as has been reported for LEF-1 (Giese and Grosschedl 1993).

Why would YY1 bend a key activator of c-fos transcription away from the basal transcription complex? One possibility is that this organization keeps promoter activity low in the absence of an overriding stimulatory signal. Activation of c-fos transcription may then be associated with a structural rearrangement of the DNA or of factors bound to the DNA. Alternatively, bending CREB away from the promoter may favor access of other factors, such as those bound at the SRE located $300 \mathrm{bp}$ upstream of the start site of transcription. A third possibility is that protein-induced bends provide a mechanism for phasing nucleosomes. Furthermore, the apparent repression by YYl may reflect our use of transiently transfected templates. In its natural context, embedded in chromatin and with all relevant transcription factors bound, YYl may not be inhibitory.

\section{Transcription factors that control promoter topology}

We propose that YYI belongs to a new class of transcription factors with the principal function of organizing promoter topology. Such factors facilitate the assembly of transcription complexes not through direct contact with other protein components, as is proposed for conventional transcription factors (Ptashne 1988; Roeder 1991, Gill and Tiian 1992) but, instead, through altering the path of the DNA helix to facilitate, in an indirect fashion, interactions among other proteins. It is likely that topology factors like YY1 are important in organizing multiprotein complexes close to the promoter as well as at large multicomponent enhancers and silencers.

Two other mammalian DNA-binding proteins have been proposed to act in a similar fashion. The lymphoidspecific HMG domain protein LEF-1 appears to activate the T-cell $\alpha$ enhancer by enabling the function of neighboring transcription factors; multimerized LEF-1 sites have no activity on their own (Giese et al. 1992). LEF-1 induces a sharp bend in DNA and can substitute for the 
bacterial protein IHF in an in vitro integration assay (Giese et al. 1992). But it is not clear that its DNA-bending activity accounts for its activity on the T-cell $\alpha$ enhancer. Indeed, LEF-1 contains an activation domain that is itself context sensitive/Giese and Grosschedl 1993|, suggesting that it may interact directly with flanking factors.

Similarly, the HMG I/Y protein has no activity on its own at the $\beta$-interferon promoter, although it is required for activation of the promoter by NF- $\mathrm{\kappa B}$ and ATF-2 (Thanos and Maniatis 1992; Du et al. 1993). Although HMG I/Y bends DNA, it has additional functions that are likely to contribute to its activity at the $\beta$-interferon promoter. Significantly, it enhances the binding of NF$\mathrm{KB}$ and ATF-2 to their binding sites in the promoter, and it interacts directly with both proteins (Du et al. 1993).

In contrast, we believe that the major, and perhaps the sole, function of YYl at the truncated c-fos promoter used in our experiments is to coordinate the positioning of the CRE and TATA elements. It has no function in the absence of a CRE, and its activities can be mimicked by changing the relative phasing of the CRE and TATA or by an unrelated DNA-bending protein. Our most striking observation is that YY1 functions as a repressor in one orientation and an activator in the other. This phenomenon is difficult to explain in terms of specific contact between YYl and flanking proteins and is simplest to understand purely in terms of an effect on DNA structure.

Our data suggest that the product of the male sex determination gene SRY may also belong to this family of transcription factors. Such a function for SRY is surprising in light of its regulatory role in development. Nevertheless, a recent comparison of SRY sequences from different mammalian species revealed a high degree of sequence divergence in regions outside the DNA-binding domain (Tucker and Lundrigan 1993; Whitfield et al. 1993), suggesting that DNA binding is the only important function of SRY. In view of our results here, one possible role of SRY may be to structurally reorganize regions of the genome that are silenced in females.

\section{Yin and yang}

YYl owes its name to its unusual functional flexibility: In some contexts, it acts as a repressor; in others, an activator. We propose that these disparate activities may reflect a single biochemical function, the ability to bend DNA. In some contexts, YYl-induced bends will appear to repress transcription as they do in the natural c-fos promoter, whereas in others they activate, as in the promoter with the reversed site. Thus, in promoters at which YYl works this way, the precise function of a given YYl site will depend on its position, orientation, and the position of flanking protein-binding sites. Changing any one of these features could affect the apparent function of a YY1 site.

In many ways, YY1 resembles the yeast proteins RAP1 and ABF1. Like YY1, these proteins have been variously characterized as activators or repressors, depending on context. RAP1 is also a DNA-bending protein (Vignais and Sentenac 1989; Gilson et al. 1993). Binding sites for RAP1 and ABFl are found in complex regulatory elements such as silencers, replication origins, and telomeres, as well as in simple promoters (Buchman et al. 1988; Diffley and Stillman 1989; Laurenson and Rine 1992). The clear though poorly understood role of RAP1 and $\mathrm{ABFl}$ at the $H M L$ and $H M R$ silencers in yeast is interesting in light of the observation that the mammalian $\epsilon$-globin gene silencer region contains at least 10 YYl sites (Gumucio et al. 1992, 1993; Peters et al. 1993). If each of these sites is occupied and bent in vivo, the consequences for DNA structure in the region of the silencer could be quite dramatic.

It is also noteworthy that $\mathrm{YY} 1$ is the target through which the adenovirus ElA oncoprotein activates the AAV P5 promoter (Shi et al. 1991). Although the mechanism of activation is unknown, E1A could activate this promoter by removing YYl or by changing its DNAbending properties. Furthermore, in cases in which YY1 activates transcription, ElA might be expected to repress promoter activity. Thus, both activation and repression by E1A could also reflect a single biochemical activity.

YY1 is an extremely abundant protein, and its DNAbinding specificity is relatively degenerate (Hahn 1992). Thus, it is possible that there are functional YY1-binding sites in many cellular genes. That YY1 is a target for E1A could account for some of the pleiotropy of ElA action in the cell. More generally, any protein that interacts physically with YY1, such as Spl (Lee et al. 1993; Seto et al. 1993), could exert its effect on promoter activity in an indirect fashion by affecting how YY1 organizes promoter DNA.

\section{Materials and methods}

\section{Plasmid construction}

The c-fos-choramphenicol acetyltransferase (CAT) reporter plasmids are based on -71 wild-type and $-71 \mathrm{pm} 3$, which have been described previously (Berkowitz et al. 1989). These plasmids served as templates for site-directed mutagenesis (Kunkel 1985) using the oligonucleotides shown below (underlines denote nucleotide substitutions or insertions relative to the wildtype c-fos promoter): - 71pm70, CAGTGACGTAGGAAGTCGTTCGTTTCACAGCG; - 71pm71, CAGTGACGTAGGAAGTCGTTCCATTCACAGCG; - 71pm72, CAGTGACGTAGGAAGTCCATCGTTTCACAGCG; - 71pm73, CAGTGACGTAGGAAATGGATGGACTCACAGCG; - 71pm74, CAGTGACGTAGGAAAACGAACGACTCACAGCG; - 71pm3/70, CACTCAGCTAGGAAGTCGTTCGTTTCACAGCG; -71pm3/ 71 , CACTCAGCTAGGAAGTCGTTCCATTCACAGCG; -71 $\mathrm{pm} 3 / 72$, CACTCAGCTAGGAAGTCCATCGTTTCACAGCG; $-71 \mathrm{pm} 3 / 73$, CACTCAGCTAGGAAATGGATGGACTCACAGCG; - 71pm3/74, CACTCAGCTAGGAAAACGAACGACTCACACG; - 71 pm75, CCAGTGACGTAGTCTAGGAAGT$\mathrm{CC}_{j}-71 \mathrm{pm} 76$, CCAGTGACGTAGTCTAGTGTAGGAAGTCC; $-71 \mathrm{pm} 77$, ATCCATTCACAGGTCTACGCTTCTATA; $-71 \mathrm{pm} 78$, ATCCATTCACAGGTCTAGTCTACGCTTCTATA.

Plasmids pBendSRE, pBend255, and pBend60, carrying the three different $\mathrm{YY} 1$ sites in the c-fos promoter, were prepared by 
inserting the following oligonucleotides into pBend2 (Kim et al. 1989) via XbaI and SalI sites: pBendSRE, CTAGATGCGGATGTCCATATTAGGACATCTTGTCGA; pBend255, CTAGATGCGGGGCCATTTATGTCGA; pBend60, CTAGATGCGGAAGTCCATCCATTGTCGA.

Phasing plasmids are made by inserting the following oligonucleotides in between $\mathrm{XbaI}$ and Sall sites in the pBend2 vector (inserted sequences are underlined): 0, CTAGATGCGGATGTCCATATTAGGACATCTATTCGCAAAAACGGGCAAAAACGGGCAAAAACGGTCGA; +2, CTAGATGCGGATGTCCATATTAGGACATCTATTGTCGCAAAAACGGGCAAAAACGGGCAAAAACGGTCGA; + 5, CTAGATGCGGATGTCCATATTAGGACATCTATTGTCGACGCAAAAACGGGCAAAAACGGGCAAAAACGGTCGA; + 7, CTAGATGCGGATGTCCATATTAGGACATCTATTGTCGACACGCAAAAACGGGCAAAAACGGGCAAAAACGGTCGA; +10 , CTAGATGCGGATGTCCATATTAGGACATCTATTGTCGACTGATCGCAAAAACGGGCAAAAACGGGCAAAAACGGTCGA.

To make pDYYl expression vector, pYY1 plasmid (Shi et al. 1991) was digested with NcoI, blunt-ended with Klenow fragment, and redigested with BamHI to release the YY1 cDNA. This fragment was cloned into the Drosophila expression vector pDAC5 (A. Wilson, unpubl.) which had been digested with $X b a I$, blunted, and digested with BamHI. To make pDSRY plasmid, the SRY CDNA was excised from pGEX-SRY (Giese et al. 1992) by digesting with EcoRI, blunting, and redigesting with $B a m H I$. The gel-purified SRY fragment was inserted into pDAC5, as described for YY1. The pDCREB plasmid was made by inserting full-length human CREB cDNA via flanking $X b a I$ and BamHI sites (Berkowitz and Gilman 1990) into pDAC5 digested with $\mathrm{XbaI}$ and $\mathrm{BamHI}$.

\section{Mobility retardation probes}

For standard mobility retardation assays, probes were prepared by PCR amplification with end-labeled primers, followed by gel purification from a nondenaturing polyacrylamide gel. For dimethylsulfate (DMS) interference assays, only a single PCR primer was end-labeled. For circular permutation assays, PCR products were synthesized with unlabeled primers flanking the tandemly duplicated polylinker and radiolabeled dATP. The fragments were then ethanol precipitated, digested with appropriate restriction enzyme, and gel purified.

\section{Purification and synthesis of proteins}

Histidine-tagged YY1 was purified over a nickel column (Biol01) as described previously (Shi et al. 1991). Human CREB (Berkowitz and Gilman 1990) was produced by in vitro transcription and translation using the TNT lysate system (Promega).

\section{Mobility retardation and DMS interference assays}

All mobility retardation reactions were performed in a $20-\mu \mathrm{l}$ reaction that contained $10 \mathrm{~mm}$ Tris- $\mathrm{Cl}(\mathrm{pH} 7.9), 1 \mathrm{~mm}$ DTT, 1 mM EDTA, 20\% glycerol, 0.05\% NP-40, $60 \mathrm{mM} \mathrm{KCl}, 5 \mu \mathrm{g}$ of BSA, $100 \mathrm{ng}$ of poly[d(I-C)], 10-20 ng of recombinant YYl, and/ or $1 \mu \mathrm{l}$ of lysate containing in vitro-translated CREB. The proteins were incubated for $10 \mathrm{~min}$ at room temperature before and after the addition of the probe. Standard assays were analyzed on $5 \%(39: 1)$ polyacrylamide gels run in $0.5 x$ Tris-borate-EDTA (TBE) buffer. Circular permutation and phasing experiments were analyzed on $6 \%$ gels.

DMS interference assays were done essentially as described by Attar and Gilman (1992). Briefly, single end-labeled PCR probes were modified with DMS, ethanol-precipitated, and resuspended in TE buffer. Approximately $50,000 \mathrm{cpm}$ of DMStreated probe was incubated with the affinity-purified YYl protein at room temperature. The YYl-DNA complex and free probes were separated by polyacrylamide gel electrophoresis in $0.5 \times$ TBE buffer. The YY1-DNA and free probe bands were excised from the gel, eluted, and ethanol precipitated. These samples were then analyzed on an $8 \mathrm{M}$ urea/10\% polyacrylamide sequencing gel.

\section{Circular permutation, phasing analyses, and calculation of bend center and angles}

For circular permutation and phasing assays, mobility retardation assays were performed using circularly permutated or phased probes and bacterially expressed YY1. The bend center and bend angles were calulated as described (Kerppola and Curran 1992). For determining bend center from the circular permutation assays, the electrophoretic mobility of each proteinDNA complex was normalized to the mobility of the fastest migrating complex in the gel and plotted as a function of the distance from the center of the YYl site to the nearest end of the probe. The bend center was estimated from the position at which this curve reached a minimum. To calculate bend angles from circular permutation assays, the ratios of the slowest to fastest migrating complexes $(\mu \mathrm{m} / \mu \mathrm{E})$ for a given probe were fitted to the equation $\mu \mathrm{m} / \mu \mathrm{E}=\cos (\alpha / 2)$, where $\alpha$ is the bend angle. For phasing analysis, bend angles were determined by calculating the ratios of the mobilities of the fastest and slowest migrating complexes and linear interpolation between points obtained with bent DNA standards (Thompson and Landy 1988).

\section{Transient expression assays}

HeLa cells were grown in Dulbecco's modified Eagle medium supplemented with $10 \%$ fetal calf serum (FCS). Drosophila SL2 cells were grown in Schneider's insect medium supplemented with $10 \%$ FCS. All transfections were performed using calcium phosphate coprecipitation as decribed (Grueneberg et al. 1992). For $\mathrm{HeLa}$ cells, $30 \%$ confluent $10-\mathrm{cm}$ plates were transfected with $3 \mu \mathrm{g}$ of reporter plasmid, and $2 \mu \mathrm{g}$ of pCH110 (Hall et al. 1983 ), which produces $\beta$-galactosidase, as an internal control. Drosophila Schneider SL2 cells were transfected with $3 \mu \mathrm{g}$ of reporter plasmid, $2 \mu \mathrm{g}$ of pACLacZ internal control plasmid, and appropriate effector plasmids ( $50 \mathrm{ng}$ of pDCREB, $5 \mu \mathrm{g}$ of pDYY1, or $5 \mu \mathrm{g}$ of $\mathrm{pDSRY}$. In all cases, total DNA concentration was adjusted to $20 \mu \mathrm{g}$ with pUC119 plasmid. CAT assays were done as described (Gorman et al. 1982). $\beta$-Galactosidase activity was measured in all extracts, and CAT assays were normalized to equivalent $\beta$-galactosidase activity. CAT assays typically contained $50-100 \mu \mathrm{g}$ of protein. In all figures, results are expressed as mean percent conversion of chloramphenicol to acetylated forms \pm S.D., on the basis of at least three independent transfections.

\section{Acknowledgments}

We thank T. Shenk, T. Kerppola, R. Grosschedl, P. Gergen, and A. Wilson for reagents; S. Bell, D. Grueneberg, N. Hernandez, and $W$. Herr for comments on the manuscript; and many colleagues for advice and ideas. This work was supported by $\mathrm{Na}$ tional Institutes of Health grant CA45642 to M.Z.G.

The publication costs of this article were defrayed in part by payment of page charges. This article must therefore be hereby 
marked "advertisement" in accordance with 18 USC section 1734 solely to indicate this fact.

\section{References}

Attar, R.M. and M.Z. Gilman. 1992. Expression cloning of a novel zinc-finger protein that binds to the c-fos serum response element. Mol. Cell. Biol. 12: 2432-2443.

Berkowitz, L.A. and M.Z. Gilman. 1990. Two distinct forms of active transcription factor CREB (cAMP response element binding protein). Proc. Natl. Acad. Sci. 87: 5258-5262.

Berkowitz, L.A., K.T. Riabowol, and M.Z. Gilman. 1989. Multiple sequence elements of a single functional class are required for cyclic AMP responsiveness of the mouse $c$-fos promoter. Mol. Cell. Biol. 9: 4272-4281.

Buchman, A.R., W.J. Kimmerly, J. Rine, and R.D. Kornberg. 1988. Two DNA-binding factors recognize specific sequences at silencers, upstream activating sequences, autonomously replicating sequences, and telomeres in Saccharomyces cerevisiae. Mol. Cell. Biol. 8: 210-225.

Chen, S., L. Mills, P. Perry, S. Riddle, R. Wobig, R. Lown, and R.L. Millette. 1992. Transactivation of the major capsid protein gene of herpes simplex virus type 1 requires a cellular transcription factor. J. Virol. 66: 4304-4314.

DeVargas, L.-M., S. Kim, and A. Landy. 1989. DNA looping generated by DNA bending protein IHF and the two domains of lambda integrase. Science 244: 1457-1461.

Diffley, J.F.X. and B. Stillman. 1989. Similarity between the transcriptional silencer binding proteins ABF1 and RAP1. Science 246: 1034-1038.

Du, W., D. Thanos, and T. Maniatis. 1993. Mechanisms of transcriptional synergism between distinct virus-inducible enhancer elements. Cell 74: 887-898.

Dynlacht, B.D., T. Hoey, and R. Tjian. 1991. Isolation of coactivators associated with the TATA binding protein that mediate transcriptional activation. Cell 66: 563-576.

Feng, J.L. and B. Villeponteau. 1990. Serum stimulation of the c-fos enhancer induces reversible changes in c-fos chromatin structure. Mol. Cell. Biol. 10: 1126-1133.

Fisher, D.E., L.A. Parent, and P.A. Sharp. 1992. Myc/Max and other helix-loop-helix/leucine zipper proteins bend DNA toward the major groove. Proc. Natl. Acad. Sci. 89: 1177911783.

Flanagan, J.R., K.G. Becker, D.L. Ennist, S.L. Gleason, P.H. Driggers, B.-Z. Levi, E. Apella, and K. Ozato. 1992. Cloning of a negative transcription factor that binds to the upstream conserved region of Moloney Murine Leukemia virus. Mol. Cell. Biol. 12: 38-44.

Giese, K. and R. Grosschedl. 1993. LEF-1 contains an activation domain that stimulates transcription only in a specific context of factor-binding sites. EMBO I. 12: 4667-4676.

Giese, K., J. Cox, and R. Grosschedl. 1992. The HMG domain of lymphoid enhancer factor 1 bends DNA and facilitates assembly of functional nucleoprotein structures. Cell 69: 185195.

Gill, G. and R. Tiian. 1992. Eukaryotic coactivators associated with the TATA-box binding protein. Curr. Opin. Genet. Dev. 2: 236-242.

Gilman, M.Z., R.N. Wilson, and R.A. Weinberg. 1986. Multiple protein-binding sites in the 5 '-flanking region regulate $\mathrm{c}$-fos expression. Mol. Cell. Biol. 6: 4305-4316.

Gilson, E., M. Roberge, R. Giraldo, D. Rhodes, and S.M. Gasser. 1993. Distortion of the DNA double helix by RAP1 at silencers and multiple telomeric binding sites. I. Mol. Biol. 231: 293-310.

Gonzalez, G.A., K.K. Yamamoto, W.H. Fischer, D. Karr, P. Men- zel, W.H. Biggs III, W.W. Vale, and M.R. Montminy. 1989. A cluster of phosphorylation sites on the cyclic AMP-regulated nuclear factor CREB predicted by its sequence. Nature 337 749-752.

Gorman, C.M., L.F. Moffat, and B.H. Howard. 1982. Recombinant genomes which express chloramphenicol acetyltransferase in mammalian cells. Mol. Cell. Biol. 2: 1044-1051.

Grueneberg, D.A., S. Natesan, C. Alexandre, and M.Z. Gilman. 1992. Human and Drosophila homeodomain protein the enhance the DNA-binding activity of serum response factor. Science 257: 1089-1095.

Gualberto, A., D. LePage, G. Pons, S.L. Mader, K. Park, M.L. Atchison, and K. Walsh. 1992. Functional antagonism between YYl and the serum response factor. Mol. Cell. Biol. 12: $4209-4214$.

Gubbay, J., J. Collignon, P. Koopman, B. Capel, A. Economou, A. Münsterberg, N. Vivian, P. Goodfellow, and R. Lovell-Badge. 1990. A gene mapping to the sex-determining region of the mouse $\mathrm{Y}$ chromosome in a member of a novel family of embryonically expressed genes. Nature 346: 245-250.

Gumucio, D.L., H. Heilstedt-Williamson, T.A. Gray, S.A. Tarlé, D.A. Shelton, D.A. Tagle, J.L. Slightom, M. Goodman, and F. Collins. 1992. Phylogenetic footprinting reveals a nuclear protein which binds to silencer sequences in the human $\gamma$ and $\epsilon$ globin genes. Mol. Cell. Biol. 12: 4919-4929.

Gumucio, D.L., D.A. Shelton, W.J. Bailey, J.L. Slighton, and M. Goodman. 1993. Phylogenetic footprinting reveals unexpected complexity in trans factor binding upstream from the 6-globin gene. Proc. Natl. Acad. Sci. 90: 6018-6022.

Gustafson, T.A., A. Taylor, and L. Kedes. 1989. DNA bending is induced by a transcription factor that interacts with the human c-fos and $\alpha$-actin promoters. Proc. Natl. Acad. Sci. 86: 2162-2166.

Hahn, S. 1992. The yin and the yang of mammalian transcription. Curr. Biol. 2: 152-154.

Hall, C.V., P.E. Jacob, G.M. Ringold, and F. Lee. 1983. Expression and regulation of Escherichia coli lacZ fusions in mammalian cells. J. Mol. Appl. Genet. 2: 101-109.

Hariharan, N., D.E. Kelly, and R.P. Perry. 1991. \&, a transcription factor that binds to downstream elements in several polymerase promoters, is a functionally versatile zinc finger protein. Proc. Natl. Acad. Sci. 88: 9799-9803.

Hoeffler, J.P., T.E. Meyer, Y. Yun, J.L. Jameson, and J.F. Habener. 1988. Cyclic AMP-responsive DNA-binding protein: Structure based on a cloned placental cDNA. Science 242: $1430-1433$.

Horikoshi, M., C. Bertuccioli, R. Takada, J. Wang, T. Yamamoto, and R.G. Roeder. 1992. Transcription factor TFIID induces DNA bending upon binding to the TATA element. Proc. Natl. Acad. Sci. 89: 1060-1064.

Kerppola, T.K. and T. Curran. 1991. Fos-Jun heterodimers and Jun homodimers bend DNA in opposite orientations: Implications for transcription factor cooperativity. Cell 66: 317326.

1992. DNA bending by Fos and Jun: Structural and functional implications. In Nucleic acids and molecular biology (ed. S. Eckstein and D.M.J. Lilley), pp. 70-105. Springer-Verlag, Berlin.

. 1993. Selective DNA bending by a variety of bZIP proteins. Mol. Cell. Biol. 13: 5479-5489.

Kim, I., C. Zwieb, C. Wu, and S. Adhya. 1989. Bending of DNA by gene regulatory proteins: Construction and use of a DNA bending vector. Gene 85: 15-23.

Kunkel, T.A. 1985. Rapid and efficient site-specific mutagenesis without phenotypic selection. Proc. Natl. Acad. Sci. 82: 488-492. 
Laurenson, R. and J. Rine. 1992. Silencers, silencing, and heritable transcriptional states. Microbiol. Rev. 56: 543-560.

Lee, J.-S., K.M. Galvin, and Y. Shi. 1993. Evidence for physical interaction between the zinc-finger transcription factors YY1 and Spl. Proc. Natl. Acad. Sci. 90: 6145-6149.

Levine, M. and J.L. Manley. 1989. Transcriptional repression of eukaryotic promoters. Cell 59: 405-408.

Lin, Y.S. and M.R. Green. 1991. Mechanism of action of an acidic transcriptional activator in vitro. Cell 64: 971-981.

Lin, Y.S., I. Ha, E. Maldonado, D. Reinberg, and M.R. Green. 1991. Binding of general transcription factor TFIIB to an acidic activating region. Nature 353: 569-571.

Ma, J. and M. Ptashne. 1987. A new class of transcriptional activators. Cell 51: 113-119.

Nash, H.A. 1990. Bending and supercoiling of DNA at the attachment site of bacteriophage lambda. Trends Biochem. Sci. 15: 222-227.

Park, K. and M.L. Atchison. 1991. Isolation of a candidate repressor/activator, NF-E1 $(Y Y 1, \delta)$ that binds to the immunoglobulin $\kappa 3$ ' enhancer and the immunoglobulin heavy chain $\mu E 1$ site. Proc. Natl. Acad. Sci. 88: 9804-9808.

Perez-Martin, J. and M. Espinosa. 1993. Protein-induced bending as a transcriptional switch. Science 260: 805-807.

Peters, B., N. Merezhinskaya, J.F.X. Diffley, and C.T. Noguchi. 1993. Protein-DNA interactions in the $\epsilon$-globin silencer. $J$. Biol. Chem. 268: 3430-3437.

Ptashne, M. 1988. How eukaryotic transcriptional activators work. Nature 335: 683-689.

Ptashne, M. and A.A.F. Gann. 1990. Activators and targets. Nature 346: 329-331.

Riggs, K.J., K.T. Merrell, G. Wilson, and K. Calame. 1991. Common factor 1 is a transcriptional activator which binds in the c-myc promoter, the skeletal $\alpha$-actin promoter, and the immunoglobulin heavy-chain enhancer. Mol. Cell. Biol. 11: 1765-1769.

Rivera, V.M. and M.E. Greenberg. 1990. Growth factor-induced gene expression: The ups and downs of $\mathrm{c}$-fos regulation. New Biol. 2: 751-758.

Roeder, R.G. 1991. The complexity of eukaryotic transcription initiation: Regulation of pre-initiation complex assembly. Trends Biochem. Sci. 16: 402-408.

Ryan, W.A., Jr., B.R. Franza Jr., and M.Z. Gilman. 1989. Two distinct cellular phosphoproteins bind to the c-fos serum response element. EMBO I. 6: 1785-1792.

Sadowski, H.B. and M.Z. Gilman. 1993. Cell-free activation of a DNA-binding protein by epidermal growth factor. Nature 362: 79-83.

Salvo, J.J. and N.D.F. Grindley. 1988. The $\gamma \delta$ resolvase bends the res site into a recombinogenic complex. EMBO J. 7: 36093616.

Sassone-Corsi, P., J. Visvader, L. Ferland, P.L. Mellon, and I.M. Verma. 1988. Induction of proto-oncogene fos transcription through the adenylate cyclase pathway: Characterization of a cAMP-responsive element. Genes \& Dev. 2: 1529-1538.

Schreck, R., H. Zorbas, E.-L. Winnacker, and P.A. Baeuerle. 1990. The NF- $\mathrm{B}$ transcription factor induces DNA bending which is modulated by its $65-\mathrm{kD}$ subunit. Nucleic Acids Res. 18: 6497-6502.

Seto, E., Y. Shi, and T. Shenk. 1991. YY1 is an initiator sequence binding protein that directs and activates transcription in vitro. Nature 354: 241-245.

Seto, E., B. Lewis, and T. Shenk. 1993. Interaction between transcription factors Spl and YY1. Nature 365: 462-464.

Shi, Y., E. Seto, L.-S. Chang, and T. Shenk. 1991. Transcriptional repression by YY1, a human GLI-Krüppel-related protein, and relief of repression by adenovirus E1A protein. Cell 67:
377-388.

Thanos, D. and T. Maniatis. 1992. The high mobility group protein $\mathrm{HMG} I(\mathrm{Y})$ is required for NF- $\mathrm{kB}$ dependent virus induction of the human IFN- $\beta$ gene. Cell 71: 777-789.

Thompson, J.F. and A. Landy. 1988. Empirical estimation of protein induced DNA bending angles: Applications to sitespecific recombination complexes. Nucleic Acids Res. 16: 9687-9705.

Travers, A.A. 1990. Why bend DNA? Cell 60: 177-180.

Tucker, P.K. and B.L. Lundrigan. 1993. Rapid evolution of the sex-determining locus in old world mice and rats. Nature 364: 715-717.

Van der Vliet, P.C. and C.P. Verrijzer. 1993. Bending of DNA by transcription factors. BioEssays 15: 25-32.

Verrijzer, C.P., J.A.W.M. Van Oosterhout, W. Wan Weperen, and P.C. Van der Vliet. 1991. POU proteins bend DNA via POU-specific domain. EMBO I. 10: 3007-3014.

Vignais, M.-L. and A. Sentenac. 1989. Asymmetric DNA bending induced by yeast multifunctional factor TUF. $J$. Biol. Chem. 264: 8463-8466.

Walsh, K. 1989. Cross-binding of factors to functionally different promoter elements in c-fos and skeletal actin genes. Mol. Cell. Biol. 9: 2191-2201.

Wang, J.C. and G.N. Giaever. 1988. Action at a distance along a DNA. Science 240: 300-304.

Wang, L., J.D. Helmann, and S.C. Winans. 1992. The A. tumefaciens transcriptional activator OccR causes a bend at a target promoter, which is partially relaxed by a plant tumor metabolite. Cell 69: 659-667.

Whitfield, L.S., R. Lovell-Badge, and P.N. Goodfellow. 1993. Rapid sequence evolution of the mammalian sex-determining gene SRY. Nature 364: 713-715.

Wu, H.-M. and D.M. Crothers. 1984. The locus of sequence directed and protein induced DNA bending. Nature 308: 509-513.

Yamamoto, K.K., G.A. Gonzalez, W.H. Biggs, and M.R. Montminy. 1988. Phosphorylation-induced binding and transcriptional efficacy of nuclear factor CREB. Nature 334: 494-498.

Zinkel, S.S. and D.M. Crothers. 1987. DNA bend direction by phase sensitive detection. Nature 328: 178-181.

1991. Catabolite activator protein-induced DNA bending in transcription activation. J. Mol. Biol. 219: 201-215. 


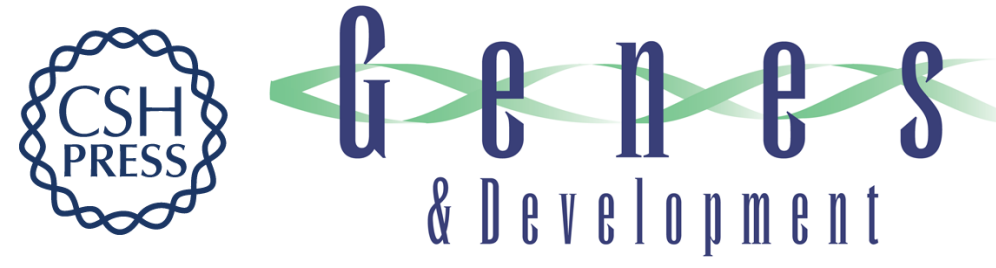

\section{DNA bending and orientation-dependent function of YY1 in the c-fos promoter.}

S Natesan and M Z Gilman

Genes Dev. 1993, 7:

Access the most recent version at doi:10.1101/gad.7.12b.2497

References This article cites 72 articles, 31 of which can be accessed free at:

http://genesdev.cshlp.org/content/7/12b/2497.full.html\#ref-list-1

License

Email Alerting

Service

Receive free email alerts when new articles cite this article - sign up in the box at the top right corner of the article or click here.

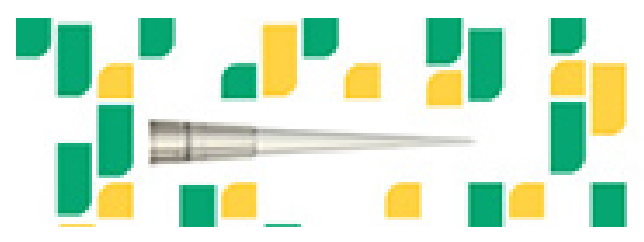

Focused on your science.

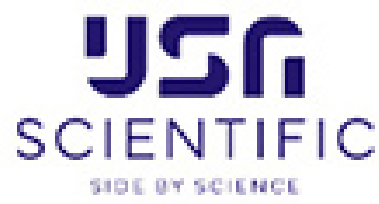

Copyright (c) Cold Spring Harbor Laboratory Press 